\title{
ChemComm
}

\section{Organometallic anticancer complexes of lapachol: metal centre-dependent formation of reactive oxygen species and correlation with cytotoxicity $\dagger$}

Cite this: Chem. Commun., 2013, 49, 3348

Received 18th January 2013, Accepted 6th March 2013

DOI: $10.1039 / c 3 c c 40432 c$

www.rsc.org/chemcomm

\author{
Wolfgang Kandioller, ${ }^{\text {ab }}$ Evelyn Balsano, ${ }^{a}$ Samuel M. Meier, ${ }^{\text {ab }}$ Ute Jungwirth, ${ }^{\text {bc }}$ \\ Simone Göschl, ${ }^{a}$ Alexander Roller, ${ }^{a}$ Michael A. Jakupec, ${ }^{\text {ab }}$ Walter Berger, ${ }^{\text {bc }}$ \\ Bernhard K. Keppler ${ }^{\mathrm{ab}}$ and Christian G. Hartinger*d
}

Organometallic Ru", Os" and Rh"' complexes of lapachol induce apoptosis in human tumour cell lines in the low $\mu \mathrm{M}$ range by a mode of action involving oxidative stress, especially in the case of the ruthenium compound.

Multi-targeted drugs are molecules whose different components impact multiple separate biotargets. ${ }^{1}$ In cancer chemotherapy this approach provides a means of overcoming major disadvantages of currently applied drugs by influencing pharmacological properties, metabolism and resistance development, enabling tuneable antitumour activity, "intramolecular combination therapy", and introduction of more selective targeted properties. ${ }^{1}$ One approach to multi-targeted compounds is the combination of anticancer metal complexes with bioactive ligands, as reported for ethacrynic acid, flavonol derivatives and other compound classes. ${ }^{2-4}$ Lapachol (2-hydroxy-3-(3-methylbut-2-en-1-yl)naphthalene-1,4-dione) and flavonols share with hydroxypyr(id)ones used in medicinal chemistry the same 5-membered ring coordination motif of $\mathrm{O}, \mathrm{O}$-bidentate anionic ligands. ${ }^{5}$ Furthermore, lapachol has antibiotic and anticancer properties and was investigated in clinical trials as an anticancer agent. ${ }^{6,7}$ Its mode of action is supposed to be related to the generation of reactive oxygen species (ROS), which harm DNA and subsequently induce apoptosis, and biologically active Bi and $\mathrm{Sb}$ complexes were reported recently. ${ }^{8,9}$ Active organometallic

\footnotetext{
${ }^{a}$ University of Vienna, Institute of Inorganic Chemistry, Währinger Str. 42, 1090 Vienna, Austria. E-mail: wolfgang.kandioller@univie.ac.at; Fax: +4314277 9526; Tel: +431427752609

${ }^{b}$ University of Vienna, Research Platform "Translational Cancer Therapy Research", Währinger Str. 42, A-1090 Vienna, Austria

${ }^{c}$ Medical University Vienna, Institute of Cancer Research and Comprehensive Cancer Center, Department of Medicine I, A-1090, Borschkegasse 8a, Vienna, Austria

${ }^{d}$ The University of Auckland, School of Chemical Sciences, Private Bag 92019, Auckland 1142, New Zealand. E-mail: c.hartinger@auckland.ac.nz; Tel: +6493737955 ext. 83220

$\dagger$ Electronic supplementary information (ESI) available: Synthetic procedures, $\mathrm{X}$-ray diffraction data, experimental procedures to mass spectrometry and biological investigations. CCDC 918728 and 918729. For ESI and crystallographic data in CIF or other electronic format see DOI: $10.1039 / \mathrm{c} 3 \mathrm{cc} 40432 \mathrm{c}$
}

$\mathrm{Ru}^{\mathrm{II}}$ (arene) complexes have clearly emerged as highly promising candidates to overcome the disadvantages of clinically-used platinum drugs. ${ }^{10}$ The RAPTA family and ethylenediamine complexes are the most prominent representatives of this compound class and are at an advanced preclinical development stage. ${ }^{11}$ Therefore, the combination of bioactive lapachol with an organometallic moiety is a promising strategy, with the metal centre altering the chemical and biological properties of the ligand.

The organometallic complexes 1a-c were synthesised by deprotonating commercially available lapachol $\mathbf{L}$ with $\mathrm{NaOMe}$ followed by conversion with the respective dimer $\left[\mathrm{MCl}_{2} \text { (arene) }\right]_{2}\left(\mathrm{M}=\mathrm{Ru}^{\mathrm{II}}\right.$ 1a, $\mathrm{Os}^{\mathrm{II}} 1 \mathrm{~b}, \mathrm{Rh}^{\mathrm{III}}$ 1c; arene $=\eta^{6}-p$-cymene for $\mathrm{Ru}^{\mathrm{II}}$, Os ${ }^{\mathrm{II}}$ and $\eta^{5}$-pentamethylcyclopentadiene for $\mathrm{Rh}^{\mathrm{III}}$ ) to the corresponding organometallics 1a-c in good to excellent yields (75-96\%). The complexes were characterised by NMR, ESI-MS and elemental analysis, confirming the proposed structure of the compounds. In addition, single crystals of $\mathbf{1 a}$ and $\mathbf{1 b}$ suitable for X-ray diffraction analysis (Table S1, ESI $\dagger$ ) were obtained from dichloromethane/ $n$-hexane by using the slow diffusion method. Complexes 1a and 1b crystallise in the monoclinic space group $P 2_{1} / n$ and adopt the pseudo-octahedral "piano-stool" configuration (Fig. 1,†), which is typical for this class of organometallic compounds. Lapachol acts as an anionic bidentate $O, O$-chelating ligand leading to the formation of a five-membered, non-planar ring with envelope conformation. The M-O2 distances were slightly shorter (2.0764(10) $\AA$ for 1a, $2.077(2) \AA$ for 1 b) than the corresponding $\mathrm{M}-\mathrm{O} 1$ bond lengths

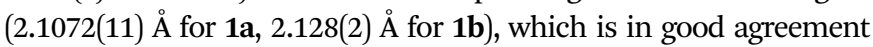
with data obtained for related organometallic complexes.

The coordination of the keto group to the metal centre induces an elongation of the $\mathrm{C}-\mathrm{O}$ bond length of the coordinated carbonyl group (1.259(4) $\AA$ for 1b) as compared to the uncoordinated carbonyl in para-position (1.240(4) ^ for 1b), which confirms the $[1,4]$-dioxo form of the attached ligand.

The aqueous chemistry of the lapachol-containing organometallics 1a-c was studied by ESI-IT-MS (Scheme 1). In all cases, aquation gave the respective aqua complexes (2a-c; Scheme 1), accompanied by ligand release and resulting in the formation of chlorido-bridged (2c) or hydroxido-bridged (2a, 2b) dimers. 


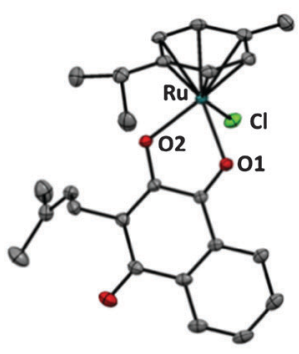

$1 \mathrm{a}$

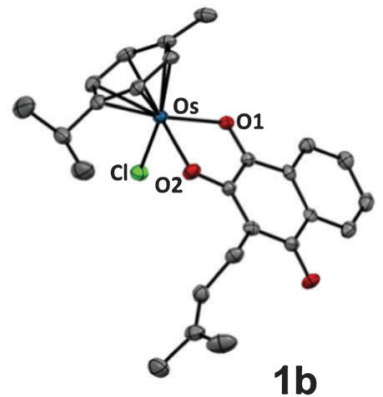

$1 \mathrm{~b}$
Fig. 1 Molecular structure of the $M^{\prime \prime}\left(\eta^{6}-p\right.$-cymene) complexes $1 a(M=R u)$ and $1 \mathrm{~b}(\mathrm{M}=\mathrm{Os})$ drawn at $50 \%$ probability level. The hydrogen atoms were omitted for clarity.

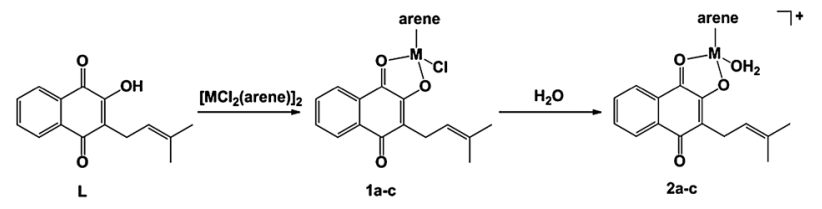

Scheme 1 Synthesis of the organometallic lapachol (L) complexes $\mathbf{1 a - c}$ and their subsequent aquation to the aqua complexes $2 \mathrm{a}-\mathrm{c}$ : (i) $\mathrm{NaOMe},\left[\mathrm{MCl}_{2} \text { (arene) }\right]_{2}$ (a $\mathrm{M}=\mathrm{Ru} \mathbf{u}^{\prime \prime}, \mathbf{b} \mathrm{M}=\mathrm{O} s^{\prime \prime}$, arene $=\eta^{6}$-p-cymene; $\mathbf{c} \mathrm{M}=\mathrm{Rh}{ }^{\mathrm{III}}$; arene = $\eta^{5}$-pentamethylcyclopentadiene).

The extent of ligand release followed the order $\mathbf{2 c}<\mathbf{2 a}<\mathbf{2} \mathbf{b}$, i.e. compound $2 \mathrm{c}$ is largely stable for at least $24 \mathrm{~h}$, while ligand release was most pronounced for $\mathbf{2 b}$ as determined by analysis of relative abundances of ions in mass spectra (see Fig. S1, ESI $\dagger$ ).

The reactivity of metal complexes towards biomolecules is a crucial parameter for their biological activity. Therefore, 1a-c were exposed to a mixture containing the DNA model 9-ethylguanine (EtG) and the amino acids glycine (Gly), L-cysteine (Cys), L-histidine (His) and L-methionine (Met). EtG adducts were only transiently formed during the first hour and were only observed for $\mathbf{1 a}$ and $\mathbf{1 b}$, while Gly adducts were not detected. Compounds 1a-c formed structurally similar products, i.e., His and mainly Met adducts detected as $[\mathrm{M}(\mathrm{aa})-\mathrm{H}]^{+}$ions $\left(\mathrm{M}=\left(\mathrm{Cp}^{*}\right) \mathrm{Rh}\right.$, (cym)Ru or (cym)Os; $\mathrm{aa}=$ His or Met). Interestingly, different reaction pathways were observed for 1a-c. 1c transiently formed Cys adducts, which disappeared again after $24 \mathrm{~h}$. A two-step binding process of amino acids was detected involving initial mono-dentate coordination of an amino acid which induces the labilisation of the $O, O$-chelate and leads ultimately to cleavage of lapachol. In contrast to 1c, 1a directly formed His and Met adducts and no other adducts were detected. For 1b, Cys adducts are stable for more than $24 \mathrm{~h}$ and were observed besides His and Met adducts (Table S2, ESI $\dagger$ ). The extent of His or Met adduct formation seems to be $\mathrm{pH}$ dependent (Fig. S2, ESI $\dagger$ ), which is of relevance in certain slightly more acidic solid tumours due to hypoxia or upregulated glycolysis. ${ }^{12}$ In such an environment, the organometallic $\mathrm{Rh}^{\mathrm{III}}, \mathrm{Ru}^{\mathrm{II}}$ and $\mathrm{Os}^{\mathrm{II}}$ compounds seem to favour thioether over imine binding. In addition, the reactivity of $\mathbf{1 a}-\mathbf{c}$ toward the model protein ubiquitin (ub) was investigated using ESI-TOF-MS. Incubation of $1 \mathbf{1 a}-\mathbf{c}$ with ub $(2: 1)$ for $24 \mathrm{~h}$ yielded primarily monoadducts accompanied by lapachol release from the metal centre (Fig. 2; Table S3, ESI $\dagger$ ). These monoadducts were then subjected to in-source collision-induced dissociation (ISCID), in order to obtain information on the binding

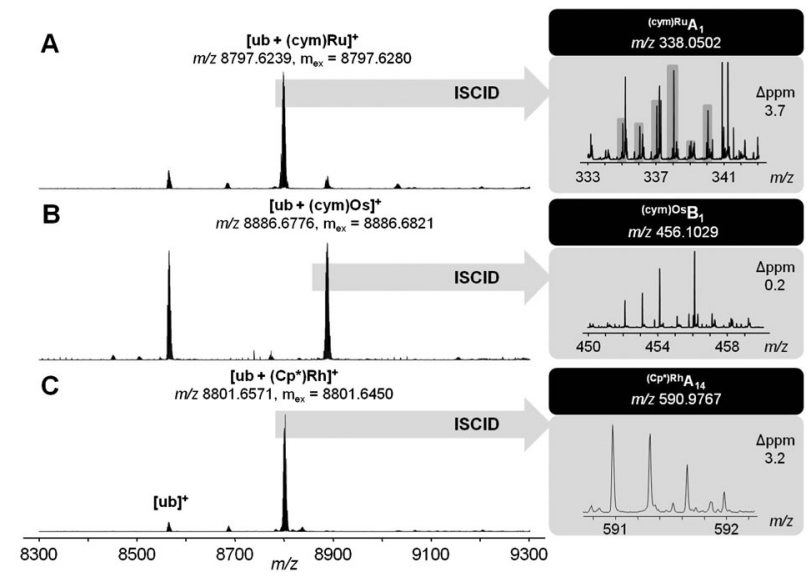

Fig. 2 Ultra-high resolution ESI-TOF mass spectra of 2:1 reaction mixtures containing $1 \mathrm{a}(\mathrm{A}), 1 \mathrm{~b}(\mathrm{~B})$ or $1 \mathrm{c}(\mathrm{C})$ and after $24 \mathrm{~h}$ (left). ISCID top-down signals of the respective mono-adduct revealed Met1 as the primary metallation site (right).

site of the metal ion on the protein. Detection of ${ }^{\mathrm{Ru}(\mathrm{cym})} \mathrm{A}_{1}$ and ${ }^{\mathrm{Os}(\mathrm{cym})} \mathrm{B}_{1}$ fragments suggest Met1 as the primary binding site for $2 \mathbf{a}$ and $2 \mathbf{b}$, as did the fragment ${ }^{\left(\mathrm{CP}^{*}\right) \mathrm{Rh}} \mathrm{B}_{3}$ for $2 \mathbf{c}$ (Table S4, ESI $\dagger$ ). To the best of our knowledge, this is the first report on binding site determination of a Rh-metallodrug on a protein in a topdown approach.

The cytotoxicity of the organometallic complexes 1a-c was determined by means of the colorimetric MTT assay in the human cancer cell lines CH1 (ovarian carcinoma), SW480 (colon carcinoma), A549 (non-small cell lung carcinoma), HCT-116 (colon carcinoma) and HL60 (acute promyelocytic leukemia) and was compared to lapachol and cisplatin (Table 1 and Fig. S3, ESI $\dagger$ ). Complexes 1a-c exhibit antitumour activity in the low $\mu \mathrm{M}$ range. In general, the activity of $\mathbf{1 b}$ was widely similar to that of lapachol (L), indicating that the ligand was the cytotoxicity-determining moiety of the compound. This may be related to ligand release in the presence of biomolecules as shown by the MS studies. The rhodium complex 1c was less cytotoxic than lapachol and more stable under physiological conditions. The organoruthenium compound 1a was the most potent compound of the series, especially in the otherwise less sensitive A549 and HCT-116 cells, where IC $_{50}$ values suggest a synergistic effect of the metal ion. The complexes induced moderate but significant levels of apoptosis as determined by means of the annexin $\mathrm{V}$ assay in SW480 cells. The amount of annexin V/PI positive cells increased significantly after addition especially of 1a and 1c, where a more than 2 -fold increase of apoptotic cells compared to the control was observed. In the cases of $1 \mathbf{a}$ and $\mathbf{1 c}$ but not $\mathbf{1 b}$

Table 1 In vitro anticancer activity ( $\mathrm{IC}_{50}$ values in $\left.\mu \mathrm{M}\right)$ of $1 \mathrm{a}-\mathrm{c}$ in $\mathrm{CH} 1, \mathrm{SW} 480$, A549, HCT-116 and HL60 cells compared to cisplatin and lapachol (L)a

\begin{tabular}{lccccc}
\hline & \multicolumn{5}{c}{$\mathrm{IC}_{50} / \mu \mathrm{M}$} \\
\cline { 2 - 6 } & CH1 & SW480 & A549 & HCT-116 & HL60 \\
\hline L & $3.3 \pm 0.2$ & $5.5 \pm 0.6$ & $42 \pm 14$ & $92 \pm 1.0$ & $18 \pm 5$ \\
1a & $4.1 \pm 0.6$ & $4.1 \pm 1.5$ & $20 \pm 5$ & $19 \pm 0.1$ & $25 \pm 0.3$ \\
1b & $4.2 \pm 0.8$ & $9.0 \pm 1.1$ & $46 \pm 8$ & $>100$ & $18 \pm 2.4$ \\
1c & $7.3 \pm 1.5$ & $39 \pm 12$ & $91 \pm 19$ & $93 \pm 0.1$ & $32 \pm 0.5$ \\
Cisplatin & $0.14 \pm 0.03^{b}$ & $3.3 \pm 0.4^{b}$ & $1.3 \pm 0.4^{b}$ & $2.7 \pm 0.7^{c}$ & -
\end{tabular}

${ }^{a} 96 \mathrm{~h}$ exposure. ${ }^{b}$ Taken from ref. $13 .^{c}$ Taken from ref. 14. 


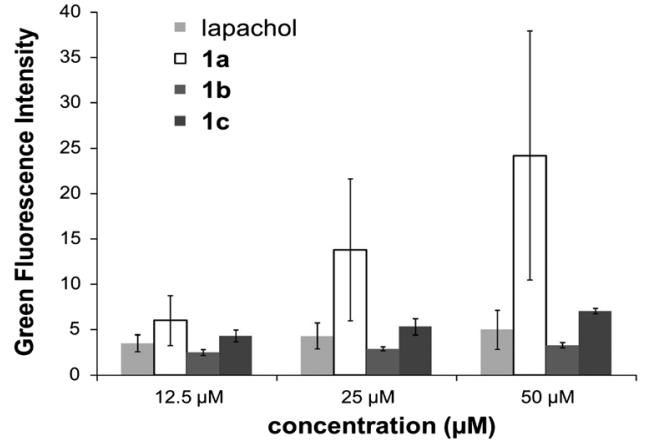

Fig. 3 Determination of the ROS level induced by lapachol and $1 \mathrm{a}-\mathrm{c}$ by the DCFH-DA-assay.

apoptosis induction was significantly enhanced as compared to L (Fig. S4, ESI + ).

The cytotoxic activity of lapachol is related to the generation of ROS and interaction with nucleic acids. ${ }^{7,15}$ Thus the potential of 1a-c to induce oxidative stress through ROS was investigated by means of the DCFH-DA assay in HL60 cells. 1a was found to generate ROS to a higher extent than the free ligand and the Os and Rh compounds (Fig. 3). The induction of oxidative stress and apoptosis was accompanied by increased phosphorylation of the stress kinase p38 and enhanced levels of p53 in HCT-116 cells (Fig. 4). These observations confirm a synergistic effect of the organoruthenium coordination to the bioactive quinone. In addition, the impact of $\mathbf{L}$ and $\mathbf{1 a}-\mathbf{c}$ on the cell cycle was investigated by FACS analysis in CH1, SW480 and HCT-116 cells (Fig. S5 and S6, ESI $\dagger$ ). Treatment of the more resistant HCT-116 cells caused a significant arrest in the G2/M phase, especially for the ruthenium complex 1a. In the case of CH1 and SW480 cells, a substantial S phase arrest was observed in the $\mathrm{IC}_{50}$ range (Fig. S5 and S6, ESI $\dagger$ ). The G1/S checkpoint is partially regulated by p53 in response to DNA damage. ${ }^{16}$ SW480 cells have a mutated p53 in contrast to HCT-116 cells, explaining the different cell cycle arrests after treatment with $\mathbf{L}$ and $\mathbf{1 a - c}$. Furthermore, our data are comparable with lapachone induced $\mathrm{S}$ phase arrest in p53 mutated cell models. ${ }^{17}$ As a consequence of the cell cycle data, the dose-dependent expression changes in cyclins and the phosphorylation of cdc2 after 24 hours were elucidated by Western blot analyses in HCT-116 cells (Fig. 4). The G2/M arrest was accompanied by expression changes of cell cycle-related proteins, such as an increase in p21, cyclin B1 and E, while cyclin D1 expression was especially enhanced at

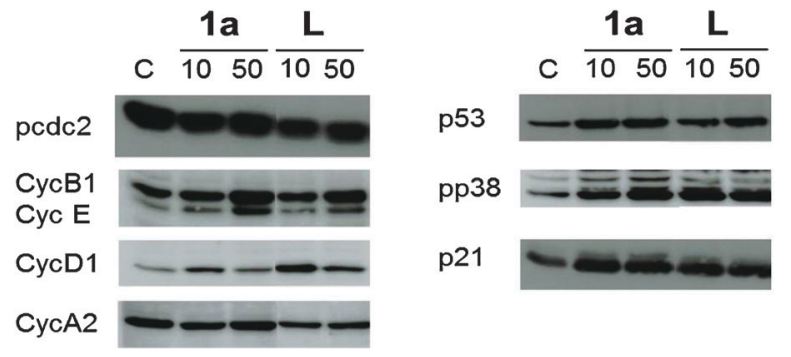

Fig. 4 Western blot analysis of HCT-116 cells incubated with $1 \mathrm{a}$ and lapachol (L) for $24 \mathrm{~h}$. lower drug concentrations. These data indicate that 1a interferes with cell cycle progression and induces apoptosis involving a p53 response.

In summary, organometallic lapachol complexes were prepared in high yields, which are activated by fast hydrolysis to the corresponding aqua species in aqueous solution. They are able to interact with biomolecules and show antiproliferative activity in the low $\mu \mathrm{M}$ range in human tumour cell lines. The first investigations of the underlying mechanisms showed an enhanced anticancer activity, especially in case of 1a, based on ROS-induced apoptosis and cell cycle arrest. Further investigations will elucidate the mode of action in more detail. Overall, the Ru complex 1a induced apoptosis to a higher degree compared to lapachol and its $\mathrm{Rh}$ and Os analogues, demonstrating a synergistic effect of the Ru centre and the bioactive ligand.

We thank the University of Vienna, the Austrian Science Fund (FWF), the Johanna Mahlke née Obermann Foundation, COST D39, CM0902 and CM1105 for financial support. We gratefully acknowledge Prof. Vladimir B. Arion for the refinement of the X-ray diffraction data and Anton A. Legin for instructions to the ROS assay.

\section{Notes and references}

† Crystallographic details: 1a: $\mathrm{C}_{25} \mathrm{H}_{27} \mathrm{ClO}_{3} \mathrm{Ru}, M_{\mathrm{r}}=511.19,0.60 \times 0.10 \times$ $0.10 \mathrm{~mm}$, monoclinic, $P 2_{1} / n, a=12.8956(5) \AA, b=11.8913(4) \AA ⿻$ 14.2756(5) ̊, $\alpha=90^{\circ}, \beta=98.504(2)^{\circ}, \gamma=90^{\circ}, V=2165.05(13) \AA^{3}, Z=4$, $\rho_{\text {calcd }}=1.571 \mathrm{mg} \mathrm{m}^{-3}, \mu=0.872 \mathrm{~mm}^{-1}, T=150(2) \mathrm{K}, 50326$ measured independent reflections, $R_{\mathrm{int}}=0.0382, R_{1}=0.0225, \mathrm{w} R_{2}=0.0595, \mathrm{GOF}=$ 1.000 ; 1b: $\mathrm{C}_{25} \mathrm{H}_{27} \mathrm{ClO}_{3} \mathrm{Os}, M_{\mathrm{r}}=601.12,0.12 \times 0.10 \times 0.02 \mathrm{~mm}$, mono-

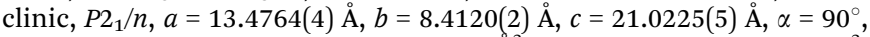
$\beta=107.9860(10)^{\circ}, \gamma=90^{\circ}, V=2266.72(10) \AA^{3}, Z=4, \rho_{\text {calcd }}=1.761 \mathrm{mg} \mathrm{m}^{-3}$, $\mu=5.767 \mathrm{~mm}^{-1}, T=150(2) \mathrm{K}, 17682$ measured independent reflections, $R_{\text {int }}=0.0426, R_{1}=0.0247, \mathrm{w}_{2}=0.0507, \mathrm{GOF}=0.997$; description of data collection and refinement see ESI; † CCDC 918728 and 918729.

1 G. R. Zimmermann, J. Lehár and C. T. Keith, Drug Discovery Today, 2007, 12, 34-42.

2 S. Chatterjee, I. Biondi, P. Dyson and A. Bhattacharyya, J. Biol. Inorg. Chem., 2011, 16, 715-724.

3 A. Kurzwernhart, W. Kandioller, C. Bartel, S. Bächler, R. Trondl, G. Mühlgassner, M. A. Jakupec, V. B. Arion, D. Marko, B. K. Keppler and C. G. Hartinger, Chem. Commun., 2012, 48, 4839-4841.

4 L. K. Filak, G. Mühlgassner, M. A. Jakupec, P. Heffeter, W. Berger, V. B. Arion and B. K. Keppler, J. Biol. Inorg. Chem., 2010, 15, 903-918.

5 W. Kandioller, A. Kurzwernhart, M. Hanif, S. M. Meier, H. Henke, B. K. Keppler and C. G. Hartinger, J. Organomet. Chem., 2011, 696, 999-1010.

6 E. Rodrigues de Almeida, Open Nat. Prod. J., 2009, 2, 42-47.

7 K. H. K. Hussain, V. U. Ahmad, G. A. Miana and I. R. Green, ARKIVOC, 2007, 2, 42-47.

8 G. Parrilha, R. Vieira, P. Campos, G. Silva, L. Duarte, S. Andrade and H. Beraldo, BioMetals, 2012, 25, 55-62.

9 L. G. de Oliveira, M. M. Silva, F. C. S. de Paula, E. C. Pereira-Maia, C. L. Donnici, C. A. de Simone, F. Frézard, E. N. da Silva Júnior and C. Demicheli, Molecules, 2011, 16, 10314-10323.

10 C. G. Hartinger, N. Metzler-Nolte and P. J. Dyson, Organometallics, 2012, 31, 5677-5685.

11 G. Süss-Fink, Dalton Trans., 2010, 39, 1673-1688.

12 R. A. Gatenby and R. J. Gillies, Nat. Rev. Cancer, 2004, 4, 891-899.

13 Y. Y. Scaffidi-Domianello, A. A. Legin, M. A. Jakupec, V. B. Arion, V. Y. Kukushkin, M. Galanski and B. K. Keppler, Inorg. Chem., 2011, 50, 10673-10681.

14 M. R. Reithofer, S. M. Valiahdi, M. Galanski, M. A. Jakupec, V. B. Arion and B. K. Keppler, Chem. Biodiversity, 2008, 5, 2160-2170.

15 E. A. Hillard, F. C. de Abreu, D. C. M. Ferreira, G. Jaouen, M. O. F. Goulart and C. Amatore, Chem. Commun., 2008, 2612-2628.

16 G. Damia and M. Broggini, Cell Cycle, 2004, 3, 46-50.

17 L. Huang and A. B. Pardee, Mol. Med., 1999, 5, 711-720. 